\title{
KNOWLEDGE, ATTITUDE AND PRACTICE OF A GROUP OF DENTAL PRACTITIONERS IN TREATING DEEP CARIOUS PRIMARY TEETH IN SAUDI ARABIA
}

\author{
Duaa Y. Wazgar ${ }^{*}$ Amani Al-Tuwirqi* and Azza A. El-Housseiny ****
}

\begin{abstract}
Preservation of sound primary tooth until eruption of the permanent successors is essential in development of normal occlusion and maintaining the arch form integrity. The study purpose was to determine the knowledge, attitude and practice regarding treating deep carious primary teeth among general dental practitioners and compared them with those of pediatric dentists in Saudi Arabia. A non-experimental, descriptive, cross sectional design was used. The study participants (170) were general dental practitioners (85) and pediatric dental practitioners (85) working in Saudi Arabia. Inclusion criteria were; enrolled in dental work in Saudi Arabia, between the ages of 26- 60 years old, had at least one-year work experience, treating children, and could read and understand English. A validated self-designed-structured questionnaire in English language was used as an instrument for data collection. Most participants were females (68\%). Highly significant differences were found between general dental practitioners and pediatric dentists in all of three aspect of the survey. This study concluded that the knowledge, attitudes and practice regarding treating deep carious lesion in primary teeth by general dental practitioners are inadequate and differ from pediatric dentists.
\end{abstract}

KEYWORDS: Primary teeth; deciduous teeth; caries; Saudi Arabia; pulp therapy; knowledge; attitude; practice; general dental practitioners; pediatric dentists

\section{INTRODUCTION}

Primary dentition is an integral unit of oral and general health that influences the quality of life ${ }^{[1]}$. Preservation of sound primary teeth until the eruption of the permanent successors is very important in the development of normal occlusion and maintaining the arch form's integrity ${ }^{[2]}$.
Badly decayed teeth result from dental caries, traumatic injury, and other causes that affect the primary and permanent teeth. Globally, the most common chronic disease in childhood is dental caries ${ }^{[3]}$. In 2003, the World Oral Health Reported that dental caries affected $60-90 \%$ of schoolchildren in industrialized countries ${ }^{[4]}$. Between1999 and 2004,

\footnotetext{
* Pediatric Dentistry Department, Faculty of dentistry, King Abdulaziz University, Jeddah, Saudi Arabia

** Pediatric Dentistry Department, Faculty of dentistry, Alexandaria University, Alexandria, Egypt
} 
the National Institute of Dental and Craniofacial Research found that $42 \%$ of children aged 2 to 11 years had dental caries in their primary teeth ${ }^{[5]}$.

Children and young adults most often develop deep carious lesions in primary and permanent teeth due to improper dental care and poor oral hygiene ${ }^{[6]}$. If not treated, carious lesions lead to deeper carious lesions, eventually involving the pulp ${ }^{[7]}$.

Permanent teeth and primary teeth are directly associated because infections in primary teeth may directly pass to permanent teeth [8]. To eliminate the infection of primary teeth, dental practitioners indicate pulp therapy or extraction of the affected teeth ${ }^{[9]}$. The treatment is based on the absence or presence of pathology, duration until normal tooth exfoliation, and vitality of the pulp. A badly decayed tooth may be non-restorable, which means that no treatment modality will help to preserve the morphological function of this tooth. The least-preferred treatment in primary teeth is extraction because space management becomes an issue ${ }^{[10]}$.

A clinician should consider pulp vitality (vital or non-vital) and the absence or presence of a radicular pathology to decide the type of pulpal therapy of the affected tooth ${ }^{[1]}$. The responsibility therefore lies with the clinician to decide the treatment modality to be done. Maintaining the vitality of the pulp of the tooth affected by caries, traumatic injury, or other possible causes is the clinician's main objective ${ }^{[12]}$.

Researchers frequently perform studies to detect the knowledge, attitudes, or practices of a group of dental practitioners regarding specific procedures or new materials in different countries ${ }^{[13]}$. Such studies have been performed in almost every part of the world, but studies that give an idea about knowledge, attitudes, and practices regarding treating primary teeth with deep carious lesions in Saudi Arabia have not yet been performed.

The lack of the dentist's knowledge or the child's cooperation could lead to wrong or incom- plete treatment of the affected tooth ${ }^{[12]}$. This leads to an increase of unnecessary extractions of primary teeth $^{[12]}$. Alongside personal care and oral hygiene, modern dental science has progressed enough to preserve teeth from decay and to maintain the teeth as long as possible ${ }^{[14]}$.

Further studies are needed to compare the knowledge, attitudes, and practices of general dental practitioners and pediatric dentists regarding dental management of carious primary teeth to distinguish what is known and done about treating carious primary teeth. It is also necessary to establish a baseline of the knowledge and practices regarding management of deep carious primary teeth and the principles of restorative therapy used by dental practitioners in Saudi Arabia.

The study's purposes were to determine the knowledge, attitude, and practice regarding treating deep carious primary teeth among general dental practitioners and compare them with those of pediatric dentists working in Saudi Arabia.

\section{MATERIALS AND METHODS}

A non-experimental, descriptive, cross sectional study was reported according to the standards of Strengthening the Reporting of Observational Studies in Epidemiology (STROBE) [15]. A total of 170 participants were divided into two groups; each contained 85 participants.

- General dental practitioners (GDPs) group, who had bachelor's certificates of dental and maxillofacial dentistry.

- Pediatric dental practitioners (PDs) group, who had master's degrees, PhDs, or board certificates in pediatric dentistry.

Inclusion criteria were enrollment in dental work in Saudi Arabia, age between 26 and 60 years, having at least 1 year of work experience, and could read and understand English. Those who were not engaged in clinical practice as well as those not 
treating children 15 years or younger were excluded.

Based on Bowen et al. ${ }^{[16]}$, we assumed that $25-$ $45 \%$ of GDPs would have correct knowledge and attitudes toward pulp therapy. It was expected that PDs would have better knowledge, attitude, and practice by at least $20 \%$. Hence, it was found that 85 participants per group were required to detect a statistically significant difference at the level of 0.05 with $80 \%$ power.

The study instrument survey was constructed based on the scientific information in the guideline of the American Academy of Pediatrics on pulp therapy for primary and immature permanent teeth ${ }^{[11]}$. The questionnaire consisted of 39 multiplechoice questions assessing four main categories: (a) demographic data, (b) oral health knowledge regarding primary teeth with deep carious lesions, (c) attitudes, and (d) practices of dental practitioners regarding treatment of deep carious lesions in primary teeth.

The socio-demographic data included participant's gender, age, nationality, place of residence (region), level of education, type of dental school, work setting, professional title, and work experience. The oral health knowledge section had 10 multiple-choice questions with three response options ("true," "false," or "don't know") that were designed to assess knowledge about deep carious lesions in primary teeth. The attitude section comprised 10 statements, with which the participants agreed or disagreed with four options ("agree," "neutral," "disagree," or "don't know") in addition to the described case scenarios. The last section had six multiple-choice case scenarios that measured participants' practice; clinical/radiographic pictures were presented to provide better information to help participants in the decision-making process.

In construction of a new measurement procedure, establishing content validity is a necessary initial task ${ }^{[17]}$. The data collection instrument used in this study was based on an online survey tool.
The study's survey was tested with six participants - three pediatric consultants and three general dental practitioners in the dental school of King Abdul-Aziz University - to assess the clarity of the survey's items and their appropriateness to the aim. Based on their feedback, minor changes were made to multiple questions in each part of study's survey.

To examine content validity, eight raters (five pediatric dentists and three general dental practitioners) from the department of pediatric dentistry at King Abdul-Aziz University reviewed all of the questionnaire items for relevance, clarity, simplicity, and ambiguity and came to some level of agreement as to which items should be included in the final questionnaire. A 4-point Likert scale [18]; the rater indicated how favorable the question was by choosing a number between 1 and 4 , where 4 indicates that the item is favorable, and 1 , that it is unfavorable. The scale content validity index (S-CVI) means the level of agreement between raters. Sangoseni et al. proposed a S-CVI of $\geq 0.78$ as a significant level for inclusion of an item into the study ${ }^{[19]}$.

To measure internal consistency reliability, one typically uses the approach of Cronbach's $\alpha$, which requires one administration of the instrument. It provides an estimate of reliability based on all possible split-half correlations for a multi-item scale. A low Cronbach's alpha indicates a lack of correlation between the scale items, which means that combining them to give an overall score is not meaningful. A high Cronbach's alpha value indicates excellent correlation, which means that some items may be redundant ${ }^{[20]}$. At the beginning of the study, eighteen inspectors (10 pediatric dentists and 8 general dental practitioners) from different work settings participated to evaluate the study survey's reliability. The internal consistency reliability was calculated for the whole sample $(n=170)$ in each aspect of the survey at the end of the study.

Twenty-two participants were invited to evaluate the test-retest reliability with a 3-week interval. 
They were from the department of pediatric dentistry at King Abdul-Aziz University and from other hospitals (governmental and private) in the cities of Jeddah and Makkah. They answered the survey manually each time, and they specified a pass code on the top of the survey paper. Each participant was given a score out of 10 for correct answers for questions at the first time then a score out of 10 for the second time in knowledge and attitude, and out of 6 for the clinical cases. The total scores of each aspect (pre and post) were compared by Interclass correlation (ICC).

A validated self-designed structured questionnaire in the English language was used as the instrument for data collection over a period of 12 weeks from April to July 2018. This study survey was uploaded as a Google Survey and then distributed online by email across the big cities of Saudi Arabia. The survey was electronically sent via the Google Survey link to all members of the Saudi Dental Society (SDS) and the Dental Administration of the Ministry of Health a total of two times over a period of 12 weeks. This study included dental practitioners who were working in government/private hospitals, primary health care centers, dental clinics, and academic universities in Saudi Arabia. Only completed surveys were included in the analysis.

Approval to conduct the study was granted by the Human Research Ethics Committee at King Abdul-Aziz University, Jeddah, Saudi Arabia. To conform to ethical considerations in conducting the research, all study participants provided their consent to participate in the research through one of the questions in the survey. A letter of information was provided to participants that explained the purpose of the study, inclusion and exclusion criteria, possible risk and harms, possible benefits, compensation, voluntary participation, confidentiality, and the author's contact information. There were not any personal identifiers in the questionnaire for confidentiality purposes.

\section{Statistical analysis:}

The data were analyzed using SPSS software (Statistical Package for the Social Sciences version 22). Descriptive analysis was performed for the variables of age, type of qualification, school type, clinical experience, work setting, and number of pediatric patients seen per week.

The frequencies of correct answers were presented in tables after excluding all "wrong" and "don't know" answers. The questionnaire consisted of three aspects: knowledge, attitude, and clinical case scenarios questions. The correct answers in every aspect were combined and compared between general dental practitioners and pediatric dentists. The value of $\mathrm{p}<0.05$ was considered as statistically significant.

A chi-square test was conducted to get the difference between GDPs and PDs in regard to their correct answers about the six clinical cases. A Mann Whitney U test was used to compare the percentage of correct answers between general practitioners and pediatric dental practitioners in regard to dental school type (governmental or private).

A t-test was used to compare the mean percentage of correct answers (to every question in the three aspects) between general practitioners and pediatric dental practitioners in regard to their clinical experience after getting their bachelor's degrees.

\section{RESULTS}

One hundred ninety completed surveys were received, of which 20 were excluded (13 of the respondents did not treat pediatric patients, and seven were younger than 26 years).

Analysis showed that the questionnaire was valid and reliable. The content validity index was 0.973 
(relevance was 0.947 , clarity was 0.925 , simplicity was 0.92 , and ambiguity was 0.893 ), which is considered as excellent content validity ${ }^{[21]}$. To assess the reliability of questionnaire, the tool was divided into four parts; Cronbach's alpha was conducted for each part separately. Although Cronbach's alpha values in the four parts were different, they ranged from good to acceptable, based on George, $2003^{[22]}$. Regarding test re-test the two answers from each participant were entered in SPSS for analysis. The resulting ICC coefficients were above 0.90 , which considered excellent ${ }^{[23]}$.

The percentage distributions of different demographic characteristic of the participants are shown in Table 1 . The majority of the participants $(68.2 \%)$ in both groups were females $(33.5 \%$ and $34.7 \%$ of GDP group and PD group, respectively). The mean age of the GDPs was $30.89 \pm 6.9$ years, and $36.03 \pm 7.5$ years for the PDs, with a range of 26-68 years. In both groups, 149 (87.6\%) participants were Saudi (42\% and $45.3 \%$ of GDP group and PD group, respectively). Most of the respondents were from Jeddah (58.3\%); the rest of them were from different regions in Saudi Arabia. The majority $(81.2 \%)$ had graduated from public/governmental dental schools. Third of GDPs (32.9\%) had less than 5 years' work experience since obtaining their bachelor's degrees. For PDs, $15.3 \%$ had less than 5 years' work experience while $20 \%$ had more than 10 years' work experience since obtaining their bachelor's degrees. Less than half (47.6\%) of PDs and $14.1 \%$ GDPs had treated more than six pediatric patients per week in their clinics. The largest group of participants (45.9\%) was working at governmental hospitals.
TABLE (1) Demographic characteristics

\begin{tabular}{|c|c|c|c|}
\hline & \multicolumn{3}{|c|}{ Frequency $(\%)$} \\
\hline & GDPs & PDs & Total \\
\hline Age $($ mean \pm SD) & $30.89 \pm 6.9$ & $36.03 \pm 7.5$ & \\
\hline Total Gender & $85(50 \%)$ & $85(50 \%)$ & $170(100 \%)$ \\
\hline Males & $28(16.5 \%)$ & $26(15.3 \%)$ & $54(31.8 \%)$ \\
\hline Females & $57(33.5 \%)$ & $59(34.7 \%)$ & $116(68.2 \%)$ \\
\hline \multicolumn{4}{|c|}{ Nationality } \\
\hline Saudi & $72(42 \%)$ & $77(45.3 \%)$ & $149(87.6 \%)$ \\
\hline Non-Saudi & $13(7.6 \%)$ & $8(4.7 \%)$ & $21(12.4 \%)$ \\
\hline \multicolumn{4}{|l|}{ Region } \\
\hline Riyadh & $6(3.5 \%)$ & $4(2.4 \%)$ & $10(5.9 \%)$ \\
\hline Eastern & $1(0.6 \%)$ & $6(3.5 \%)$ & $7(4.1 \%)$ \\
\hline Makkah & $20(11.8)$ & $17(10 \%)$ & $37(21.8 \%)$ \\
\hline Madinah & $3(1.8 \%)$ & $1(0.6 \%)$ & $4(2.4 \%)$ \\
\hline Jeddah & $46(27.1 \%)$ & $53(31.2 \%)$ & $99(58.3 \%)$ \\
\hline Asir & 0 & $1(0.6 \%)$ & $1(0.6 \%)$ \\
\hline Baha & $1(0.6 \%)$ & $1(0.6 \%)$ & $2(1.2 \%)$ \\
\hline Other & $8(4.7 \%)$ & $2(1.2 \%)$ & $10(5.9 \%)$ \\
\hline \multicolumn{4}{|c|}{ Work setting } \\
\hline Private Hospt & $17(10 \%)$ & $22(12.9 \%)$ & $39(22.9 \%)$ \\
\hline Private Clinic & $2(1.2 \%)$ & $2(1.2 \%)$ & $4(2.4 \%)$ \\
\hline Governmental & $33(19.4 \%)$ & $45(26.5 \%)$ & 78(45.9\%) \\
\hline PHC & $15(8.8 \%)$ & $2(1.2 \%)$ & $17(10 \%)$ \\
\hline Academic & $16(9.4 \%)$ & $14(8.2 \%)$ & $30(17.6 \%)$ \\
\hline Others & $2(1.2 \%)$ & 0 & $2(1.2 \%)$ \\
\hline \multicolumn{4}{|c|}{ Dental School } \\
\hline Private & $26(15.3 \%)$ & $6(3.5 \%)$ & $32(18.8 \%)$ \\
\hline Public & $59(34.7 \%)$ & $79(46.5 \%)$ & $138(81.2 \%)$ \\
\hline \multicolumn{4}{|c|}{ Work Experience } \\
\hline$<5$ years & $56(32.9 \%)$ & $26(15.3 \%)$ & $82(48.2 \%)$ \\
\hline $5-10$ years & $17(10 \%)$ & $25(14.7 \%)$ & $42(24.7 \%)$ \\
\hline$>10$ years & $12(7.1 \%)$ & $34(20 \%)$ & $46(27.1 \%)$ \\
\hline \multicolumn{4}{|c|}{ Number of pediatric patients seen per week } \\
\hline$<3$ & $44(25.9 \%)$ & $12(7.1 \%)$ & $56(33 \%)$ \\
\hline $3-6$ & $17(10 \%)$ & $16(9.4 \%)$ & $33(29.4 \%)$ \\
\hline$>6$ & $24(14.1 \%)$ & $81(47.6 \%)$ & $105(61.7 \%)$ \\
\hline
\end{tabular}

\section{GDPs: General dental practitioners}

PDs: Pediatric dentists

SD: Standard deviation 
In Table 2, dentists were asked about the source with which they updated their knowledge of dentistry; most of the GDPs $(32,18.8 \%)$ and PDs $(35,20.6 \%)$ used more than one source, combining books, American Academy of Pediatric Dentistry (AAPD), and Continuing education (CE) courses.

TABLE (2) Source of updates in dentistry

\begin{tabular}{lccc} 
& GDPs & PDs & Total \\
\hline Books & $22(12.9 \%)$ & $9(5.3 \%)$ & $31(18.2 \%)$ \\
\hline $\begin{array}{l}\text { American Academy } \\
\text { of Pediatric Dentistry }\end{array}$ & $13(7.6 \%)$ & $3(22.4 \%)$ & $16(30 \%)$ \\
\hline $\begin{array}{l}\text { Continuing } \\
\text { education courses }\end{array}$ & $12(7.1 \%)$ & $3(1.8 \%)$ & $15(8.9 \%)$ \\
\hline I don't update & $4(2.4 \%)$ & 0 & $4(2.4 \%)$ \\
\hline Other & $2(1.2 \%)$ & 0 & $2(1.2 \%)$ \\
\hline $\begin{array}{l}\text { Combined (more } \\
\text { than one resource) }\end{array}$ & $32(18.8 \%)$ & $35(20.6 \%)$ & $67(39.4 \%)$ \\
\hline
\end{tabular}

\section{GDPs: General dental practitioners}

PDs: Pediatric dentists

Exact 66 pediatric dentists $(77.6 \%)$ had completed their postgraduate education in Saudi Arabia, nine of them (10.6\%) in North America, and five $(5.9 \%)$ in Europe. Most pediatric dentists $(62.3 \%)$ had fewer than 5 years' work experience since obtaining their postgraduate education, $25.9 \%$ had 5-10 years' work experience, and $11.8 \%$ had more than 10 years' experience.

\section{Knowledge:}

From Table 3, significant difference was found between GDPs and PDs in question \#2 $(\mathrm{P}<0.01)$, general dental practitioners demonstrated insufficient background knowledge about the Hall technique, as most of them (55.2\%) answered incorrectly when they were asked about the definition of this technique. On the other hand, $80 \%$ of pediatric dentists were familiar with the Hall technique. Also, in question $5,23.5 \%$ of GDPs preferred amalgam/composite restoration as the final restoration after pulpotomy in primary teeth, which was an incorrect answer, while $91.8 \%$ of PDs preferred SSC restoration after pulpotomy in primary teeth. Regarding question 6; $47.1 \%$ of GDPs did not believe that primary tooth pulpotomies should be at least annually evaluated radiographically to detect any changes that need intervention, but $74.1 \%$ of pediatric dentist believed this. As shown in Table 3, question \#8, 60\% of general dental practitioners believed that indirect pulp capping (IPC) had a lower success rate than pulpotomy in primary teeth (incorrect answer), while $60 \%$ of pediatric dentists trusted that IPC had a higher success rate than pulpotomy in primary teeth (correct answer).

In Table 3, question \#9 shows that $31.8 \%$ of general dental practitioners didn't think that MTA performed equally to or better than ferric sulfate when used for pulpotomies in primary teeth, but most pediatric dentists (85.9) thought it was, which was the correct answer.

\section{Attitude}

As shown in Table 4, significant difference was found between GDPs and PDs $(\mathrm{P}<0.01)$ regarding question \#2, only (49.4\% of GDPs disagreed with using interim therapeutic restorations (ITR) with glass ionomers to control caries in teeth with carious lesions that exhibit signs of irreversible pulpitis in primary teeth, while most of the pediatric dentists $(82.3 \%)$ disagreed with that (disagree was the correct answer), $\mathrm{p}<0.01$. On question 3, 76.5\% of PDs and only $56.5 \%$ of GDPs considered indirect pulp treatment in primary teeth with no pulpitis or with signs of reversible pulpitis when the deepest carious dentin is not removed to avoid pulp exposure (correct answer), $\mathrm{p}<0.01$.

Regarding question \#5, 45.8\% of GDPs but $71.8 \%$ of PDs didn't believe that calcium hydroxide has longer-term success than formocresol in pulpotomy of primary teeth (correct answer), $\mathrm{p}<0.01$. On question \#9, $62.3 \%$ of general dental practitioners 
and $84.7 \%$ of pediatric dentists believed that apexification is contraindicated for primary teeth (correct answer). On the last question, 76.5\% of GDPs and
94.1\% of PDs believed that direct pulp capping of a carious pulp exposure in primary teeth is not recommended (correct answer), $\mathrm{p}<0.01$.

TABLE (3) Differences between General Dentists and Pediatric dentists in Knowledge (correct answers)

\begin{tabular}{|c|c|c|c|c|}
\hline \multirow[b]{2}{*}{ Knowledge Questions } & \multicolumn{2}{|c|}{ Professional Title } & \multirow[b]{2}{*}{$\mathrm{X}^{2}$} & \multirow[b]{2}{*}{ P Value } \\
\hline & GDPs & PDs & & \\
\hline Q1 Suitable root canal filling material & $75(88.2 \%)$ & $75(88.2 \%)$ & 0 & 1 \\
\hline Q2 Hall.technique & $38(44.7 \%)$ & $68(80 \%)$ & 22.5 & $<0.01$ \\
\hline Q3 Contraindications of pulpotomy & $46(54.1 \%)$ & $55(64.7 \%)$ & 1.9 & 0.16 \\
\hline Q4 Complete removal of carious lesion & $82(96.5 \%)$ & $77(90.6 \%)$ & 2.4 & 0.1 \\
\hline Q5 Final restoration after pulpotomy of primary & $65(76.5 \%)$ & $78(91.8 \%)$ & 7.4 & 0.01 \\
\hline Q6 Radiographic evaluation of primary tooth Pulpotomies & $45(52.9 \%)$ & $63(74.1 \%)$ & 8.2 & $<0.01$ \\
\hline Q7 Protective liner in a deep area of the cavity Preparation & $73(85.9 \%)$ & $73(85.9 \%)$ & 0 & 1 \\
\hline Q8 Success rate of indirect pulp capping & $34(40 \%)$ & $51(60 \%)$ & 6.8 & $<0.01$ \\
\hline Q9 MTA for pulpotomies in primary teeth & $58(68.2 \%)$ & $73(85.9 \%)$ & 7.5 & $<0.01$ \\
\hline Q10 Indication of direct pulp capping in primary teeth & $48(56.5 \%)$ & $42(49.4 \%)$ & 0.8 & 0.22 \\
\hline
\end{tabular}

GDPs: General dental practitioners

PDs: Pediatric dentists

X2 : Chi square test

TABLE (4) Frequencies of correct answers for attitude toward pediatric dentistry questions

\begin{tabular}{|l|c|c|c|c|}
\hline & GDPs & PDs & $\mathbf{X}^{2}$ & P-value \\
\hline Q1 Reversible pulpitis & $58(68.2 \%)$ & $61(71.8 \%)$ & 0.25 & 0.6 \\
\hline Q2 ITR & $42(49.4 \%)$ & $70(82.3 \%)$ & 20 & $<\mathbf{0 1}$ \\
\hline Q3 IPT & $48(56.5 \%)$ & $65(76.5 \%)$ & 7.6 & $<.01$ \\
\hline Q4 1\% sodium hypo & $51(60 \%)$ & $60(70.6 \%)$ & 2.1 & 0.1 \\
\hline Q5 Calcium Hydr & $39(45.8 \%)$ & $61(71.8 \%)$ & 11.7 & $<0.01$ \\
\hline Q6 Quality of treatment & $58(68.2 \%)$ & $63(74.2)$ & 0.7 & 0.39 \\
\hline Q7 Success & $20(23.5 \%)$ & $21(24.7 \%)$ & 0.03 & 0.8 \\
\hline Q8 Haemorrhage & $43(50.6 \%)$ & $52(61.1 \%)$ & 1.9 & .16 \\
\hline Q9 Apexification & $53(62.3 \%)$ & $72(84.7 \%)$ & 10.9 & $<\mathbf{0 . 0 1}$ \\
\hline Q10 Capping & $65(76.5 \%)$ & $80(94.1 \%)$ & 10.5 & $<\mathbf{0 . 0 1}$ \\
\hline
\end{tabular}




\section{Practice}

In clinical case 1, dental practitioners were asked to recommend treatment for localized swelling related to a carious an upper primary first molar without any systemic manifestation. Only45.9\% of general dentists and $76.5 \%$ pediatric dentists recommended extraction of the affected tooth and space management, which was the correct answer for this case. As shown in Table 5, there was a significant difference between the two groups $\left(\mathrm{X}^{2}=16.7, \mathrm{p}<0.01\right)$.

Case 2 requested a treatment recommendation for pain during eating related to a carious lower second primary molar, when, on caries' removal, an exposure occurred. General and pediatric dentists recommended pulpotomy (correct answer) as a treatment option, with $74.1 \%$ and $85.9 \%$, respectively. As shown in Table 5, there was no significance difference between the two groups $\left(\mathrm{X}^{2}=3.6, \mathrm{p}=0.06\right)$.

Case 3 requested a treatment recommendation for a deep carious lesion with pain during eating on a lower primary first molar, if the dentist removed the deepest carious dentin, the pulp would be exposed. Thirty-six (42.4\%) general dentists and 48 pediatric dentists $(56.5 \%)$ recommended indirect pulp treatment with calcium hydroxide, which was the correct answer. General dentists and pediatric dentists were not statistically different from each other in answering the third case as shown in Table $7\left(\mathrm{X}^{2}=3.3, \mathrm{p}=0.07\right)$.

In Case 4, the dentists were asked to recommend treatment for a 5-year-old patient with a carious lower primary second molar without radiographic signs of infection, where during pulpotomy procedure, there was excessive uncontrolled bleeding. The majority of general dental practitioners (68.2\%) and pediatric dentists $(82.1 \%)$ recommended pulpectomy, which was the correct answer. General dental practitioners and pediatric dentists were statistically different from each other in answering the fourth case, as shown in Table $5\left(\mathrm{X}^{2}=4.55, \mathrm{p}=0.03\right)$.
Case 5 requested a treatment recommendation for lower first primary molar with mesial and distal carious lesions. Sixty-eight percent of general dental practitioners and almost $85 \%$ of pediatric dentists recommended a preformed metal crown, which was the correct answer. Treatment decision of GDPs differed significantly from that of PDs for the fifth case, as shown in Table $5\left(\mathrm{X}^{2}=0.7, \mathrm{p}=0.006\right)$.

In Case 6, the dentists were asked to recommend treatment for a 5-year-old girl complaining of spontaneous pain during the night in lower first primary molar. The correct answer for managing this affected tooth was extraction. Almost $20 \%$ of general dental practitioners and $24 \%$ of pediatric dentists recommended extraction of this tooth. General dental practitioners and pediatric dentists were statistically different from each other in answering the sixth case, as shown in Table 5 $\left(X^{2}=17.65, p=0.001\right)$

TABLE (5) Frequencies of correct answers of clinical cases

\begin{tabular}{lcccc}
\hline & GDPs & PDs & $\mathbf{X}^{2}$ & P-value \\
\hline Case 1 & $39(45.9 \%)$ & $65(76.5 \%)$ & 16.7 & $<\mathbf{0 . 0 1}$ \\
\hline Case 2 & $63(74.1 \%)$ & $73(85.9 \%)$ & 3.6 & 0.06 \\
\hline Case 3 & $36(42.4 \%)$ & $48(56.5 \%)$ & 3.3 & 0.07 \\
\hline Case 4 & $58(68.2 \%)$ & $70(82.4 \%)$ & 4.55 & $\mathbf{0 . 0 3}$ \\
\hline Case 5 & $58(68.2 \%)$ & $73(85.9 \%)$ & 0.7 & $\mathbf{0 . 0 0 6}$ \\
\hline Case 6 & $17(20 \%)$ & $38(44.7 \%)$ & 11.8 & $<\mathbf{0 . 0 1}$ \\
\hline
\end{tabular}

GDPs: General dental practitioners

PDs: Pediatric dentists

$X^{2}:$ Chi square test

\section{Knowledge, attitude, and practice}

Within the limitations of the study, each participant's total number of correct answers in the three aspects (knowledge, attitude, and clinical 
cases) was presented as a percentage. The mean and standard deviation of the total percentage for all participants was calculated (Table 6). There were highly significant differences between GDPs and PDs in all three aspects of the survey. General dental practitioners showed less awareness and deficient therapeutic approaches regarding treatment of deep carious lesions in primary teeth compared with pediatric dentists.

TABLE (6) Total Correct answers in all three aspects among both groups (GPs and PDs)

\begin{tabular}{|c|c|c|c|c|}
\hline Category & GDPs & PDs & T test & P-value \\
\hline $\begin{array}{c}\text { Knowledge } \\
\text { Questions (10) }\end{array}$ & $68.3 \pm 15.1$ & $75 \pm 13.1$ & -3.09 & $\mathbf{0 . 0 0 2}$ \\
\hline $\begin{array}{c}\text { Attitude } \\
\text { Questions (10) }\end{array}$ & $56.1 \pm 19.2$ & $71.2 \pm 17.6$ & -5.3 & $<\mathbf{0 . 0 1}$ \\
\hline $\begin{array}{c}\text { Clinical } \\
\text { Cases (6) }\end{array}$ & $53.1 \pm 24.7$ & $71.9 \pm 23.8$ & -5.04 & $<\mathbf{0 . 0 1}$ \\
\hline
\end{tabular}

\section{GDPs: General dental practitioners}

PDs: Pediatric dentists

\section{DISCUSSION}

In this study, a comparative evaluation was carried out to evaluate the knowledge, attitudes and practice of general dental practitioners and pediatric dentists in treating deep carious primary teeth with the aid of a structured questionnaire. Significant differences were found between GDPs and PDs in treatment decision.

Treatment of a deep carious lesion depends on multiple findings: pulp involvement, periapical inflammation, pulp vitality, restorability of the affected tooth, and time till exfoliation of the tooth. The affected tooth could be vital (no symptoms and normal response to vitality test), have inflamed vital pulp but be able to heal (reversible pulpitis), have inflamed vital pulp that is unable to heal, or not have vital pulp (necrotic pulp) ${ }^{[11]}$. Regarding their knowledge, most GDPs and PDs were similar in following the guidelines of the American Academy of Pediatrics Dentistry regarding complete removal of a carious lesion before pulp therapy of the affected tooth and the use of a protective liner in a deep cavity ${ }^{[11]}$.

The success rate of primary tooth pulpotomies diminishes over time, so radiographic evaluation of the treated tooth should be repeated at least yearly ${ }^{[11]}$. Most PDs (74\%) and GDPs (52.9\%) agreed with that. A previous study in the Netherlands found that PDs took more radiographs than GDPs ${ }^{[24]}$.

The Hall technique is a minimal intervention method that does not require local anesthesia or tooth preparation. It is indicated for asymptomatic carious primary molars to manage the progression of caries using a preformed metal crown to seal the decay ${ }^{[25]}$. Almost $55.3 \%$ of GDPs responded that they did not know about this method. This reflects that GDPs are not sufficiently aware about new techniques regarding pediatric dentistry and lack adequate practice and confidence.

Both groups preferred to use indirect pulp capping over pulpotomy when the pulp is normal or has a diagnosis of reversible pulpitis. This result has been supported by other studies ${ }^{[16,26]}$. Most pediatric dentists $(82.3 \%)$ disagreed with using interim therapeutic restorations (ITR) with glass ionomers to control caries in teeth with carious lesions that exhibit signs of irreversible pulpitis, while the majority $(50.6 \%)$ of GDPs agreed. General dental practitioners disliked performing complex procedures more than the pediatric dentists.

Regarding the attitude questions that asked about the indication and contraindication of direct pulp capping and indirect pulp capping in primary teeth, GDPs preferred not to perform these procedures in primary teeth. This could be because in dental school, students more often performed IPC and DPC on permanent teeth, so they unconsciously linked them to permanent teeth only. 
Apexification is inducing the development of an uncompleted tooth root or closure of the root apex by deposition of hard tissue ${ }^{[27]}$. It is a treatment option for a traumatic/fractured permanent tooth with pulp involvement. This procedure is not recommended for primary teeth ${ }^{[1]}$. More than half of general dental practitioners (62.3\%) and $84.7 \%$ of pediatric dentists did not recommend performing apexification on primary teeth.

Based on the guideline of the American Academy of Pediatric Dentistry on pulp therapy for primary and permanent teeth, the recommended final restoration after pulpotomy treatment in a primary tooth is a preformed metal crown. In this study, almost $32 \%$ of GDPs recommended composite or amalgam as the final restoration of a primary tooth after pulpotomy treatment ${ }^{[28]}$. This can be attributed to either lack of skill among general dental practitioners or the easy availability of composite/amalgam restorations. A previous study suggested that predoctoral dental students have few chances to place stainless steel crowns on pediatric patients ${ }^{[29]}$.

In Case 6, the dentists were asked to recommend a treatment for a 5-year-old girl complaining of spontaneous pain during the night in lower first primary molar. The correct answer for managing this affected tooth was extraction. Almost half of general dental practitioners (47\%) recommended pulpotomy of the affected tooth, $22.34 \%$ recommended pulpectomy, and only $20 \%$ recommended extraction. This reflects the awareness of the general dental practitioners about the importance of preserving the primary teeth to the dental arch but also reflects their misunderstanding regarding selection and application of treatment modalities for primary tooth pulp therapy. Another study conducted in Saudi Arabia found that GDPs did not recommend extraction as the first treatment option for primary teeth ${ }^{[12]}$.

A significant difference was observed between general dental practitioners and pediatric dentists regarding their knowledge, attitudes, and practices toward treating deep carious lesions in primary teeth. This finding suggests that the pediatric dentists had higher levels of dental knowledge, extended positive attitude, and practice toward the significance of pediatric operative therapy. We can overcome this through continuous education programs regarding treatment recommendations for deep carious primary teeth. This is a way for general dentists to keep up to date in their field, so they do not fall behind.

There was no significant difference among GDPs according to their type of dental school (public or private) regarding knowledge, attitude, or practice questions. This reflects that public and private dental schools have the same curriculum and teaching method regarding pediatric dentistry.

Most of the correct answers were chosen by GDPs who had less than 5 years' work experience. This finding indicates that newly graduated GDPs received enough and updated education and clinical training in Saudi dental schools. Meanwhile, most of the pediatric dentists who answered correctly had more than 10 years' work experience. This could be explained by the fact that the more experience they have, the better their treatment decisions will be.

One of the areas of importance of this study is that it explored the disparity in understanding and beliefs between GDPs and PDs in Saudi Arabia in managing primary teeth with deep carious lesions. Such findings highlight the importance of directing general dental practitioners on treating primary teeth. Training GDPs to handle pediatric dental patients with deep carious lesions might be another goal to consider and develop. All GDPs should be aware of all the latest advancements regarding caries' management in pediatric dentistry to strengthen their practices and confidence.

This study has some limitations. First, it had a cross-sectional study design; consequently, it could not establish a causal or temporal relationship among the variables. Second, it had a small sample size and used a convenience sampling method; future research is required using a larger sample size. 
Third, to reach a broader demographic area, the survey was distributed using an online link. However, such method might have not reached those respondents who can only respond by alternative usual approaches like papers. Finally, there were no relevant studies available focusing on this topic among general dental practitioners in Saudi Arabia, so the direct comparison of the study results with those of prior studies was limited.

The study findings indicate that the attitudes and practices of general dental practitioners need improvement, and the population would benefit if general dentists underwent common, essential, standardized training courses regarding the treatment of primary teeth. More emphasis should be given to diagnosis and treatment recommendations for pediatric patients at both undergraduate and postgraduate levels, and more time spent putting these skills into practice.

The current study could be used as a baseline for defining the current status of dental practitioners' awareness of how to treat deep carious lesions in primary teeth. Further assessment regarding the practices and understanding of general dental practitioners regarding the same issue is still needed. General dental practitioners' familiarity and expertise in dealing with such dental pediatric cases that require assessment of restorability and/or pulp therapy also need to be carefully assessed for proper action to be taken.

\section{CONCLUSIONS}

This study concluded that the knowledge, attitudes, and practices regarding treating deep carious lesions in primary teeth among general dental practitioners are inadequate and differ from pediatric dentists. Therefore, a dental awareness program needs to be introduced to address this concern.

Author Contributions: DYW conception of the idea, contributed in study design, development of the questionnaire, data collection and interpretation, writing first draft. AA contributed in study design, contributed in data acquisition and revised the manuscript. AAE contributed in conception of the idea and development of the questionnaire, contributed in study design, editing and critically revised the manuscript. All authors read and approved the final manuscript.

Funding: "This research received no funding"

Conflicts of Interest: "The authors declare no conflict of interest."

\section{REFERENCES}

1- Sheiham, A. Oral health, general health and quality of life. Builletin of the World Health Organization 2005, 83, 644.

2- Setia V, Pandit IK, Srivastava N, Gugnani N, Sekhon HK. Space maintainers in dentistry: Past to present. J Clin Diagn Res 2013,7, 2402-5.

3- Douglass, J. M., Douglass, A. B., Silk, H. J. A practical guide to infant oral health. American Family Physician 2004, 70, 2113-2120.

4- World Health Organization. What is the burden of oral disease?. Available at WWW.who.int/oral_health/disease_ burden/global/en/. [Last accessed July 2018]

5- National Institute of Dental and Craniofacial Research. Dental caries Tooth decay in children age 2 to 11. Available at: https://www.nidcr.nih.gov/research/data-statistics/ dental-caries/children. [Last accessed July 2018]

6- Patil, P. D., Katge, A. F., Rusawat, D. B. Knowledge and attitude of pediatric dentists, general dentists, postgraduates of pediatric dentistry, and dentists of other specialties toward the endodontic treatment of primary teeth. Journal of Orofacial Sciences 2016, 8, 96.

7- McDonald, R. E., Avery, D. R., Dean, J. A. Treatment of deep caries, vital pulp exposure, and pulpless teeth. McDonald and Avery's Denitstry for the Child and Adolescent 2010, 9, 343-365.

8- Mariela Rodriguez Cordeiro, M., \& Jose de Carvalho Rocha, M. The effects of periradicular inflamation and infection on a primary tooth and permanent successor. Journal of Clinical Pediatric Dentistry 2005, 29, 193-200.

9- Mani, S. A., Aziz, A. A., John, J., Ismail, N. M. Knowledge, attitude and practice of oral health promoting factors among caretakers of children attending day-care centers 
in Kubang Kerian, Malaysia: A preliminary study. Journal of Indian Society of Pedodontics and Preventive Dentistry 2010, 28, 78 .

10- Garcia-Godoy, F. Evaluation of an iodoform paste in root canal therapy for infected primary teeth. ASDC Journal of Dentistry for Children 1987, 54, 30-34.

11- American Academy of Pediatric Dentistry. Guideline on pulp therapy for primary and young permanent teeth. Pediatric Dentistry 2015, 37, 144-148.

12- Togoo, R., Zakirulla, M., Yaseen, S., Nasim, V. Knowledge and practice of pulp therapy in deciduous teeth among general dental practitioners in Saudi Arabia. Annals of Medical and Health Sciences Research 2012, 2, 119.

13- Figueiredo, R.L.F., Hwang, S. W., Quiñonez, C. Dental health of homeless adults in Toronto, Canada. Journal of Public Health Dentistry 2013, 73, 74-78.

14- Dye, B. A., Tan, S., Smith, V., Barker, L. K., ThorntonEvans, G., Eke, P. I., Beltrán-Aguilar, E. D. Trends in oral health status; United States, 1988-1994 and 1999-2004 Vital Health Stat 11 2007, 11, 1-92.

15- von Elm, E., Altman, D.G., Egger, M., Pocock, S. J., Gøtzsche, P. C., \& Vandenbroucke, J. P. The strengthening the reporting of observational studies in epidemiology (STROBE) statement: Guidelines for reporting observational studies. International Journal of Surgery, 2014, 12, 1495-1499.

16- Bowen, J. L., Mathu-Muju, K. R., Nash, D. A., Chance, K. B., Bush, H. M., Li, H.-F. Pediatric and general dentists' attitudes toward pulp therapy for primary teeth. Pediatric Dentistry 2012, 34, 210-215.

17- Haynes, S. N., Richard, D. C. S., Kubany, E. S. Content Validity in Psychological Assessment: A Functional Approach to Concepts and Methods. Psychological Assessment 1995, 7, 238-247.

18- Waltz, C. F., \& Bausell, R. B. Nursing research: Design, statistics, and computer analysis. Philadelphia: F.A. Davis Co., 1981.

19- Sangoseni, O., Hellman, M., Hill, C. Development and Validation of a questionnaire to assess the effect of online learning on behaviors, attitudes, and clinical prac- tices of physical therapists in the United States regarding evidenced-based clinical practice. The Internet Journal of Allied Health Sciences and Practice 2013, 11, 1-12.

20- Gilchrist, F., Rodd, H., Deery, C., Marshman, Z. Assessment of the quality of measures of child oral health-related quality of life. BMC Oral Health 2014,14, 1-17.

21- Shi, J., Mo, X., Sun, Z. Content validity index in scale development. Journal of Central South University. Medical sciences 2012, 37,152-5.

22- Mallery, P., George, D. SPSS for Windows step by step: a simple guide and reference 11.0 update (4th ed.). Allyn, Bacon, Boston 2003,1-63.

23- Koo, T. K., \& Li, M. Y. A guideline of selecting and reporting intraclass correlation coefficients for reliability research. Journal of Chiropractic Medicine, 2016, 15, 155-163.

24- Schorer-Jensma, M. A., Veerkamp, J. S. A comparison of paediatric dentists' and general dental practitioners' care patterns in paediatric dental care. European Archives of Paediatric Dentistry: Official Journal of the European Academy of Paediatric Dentistry 2010, 11, 93-96.

25- Ghaith, B., Hussein, I. the Hall Technique in Paediatric Dentistry: a Review of the Literature and an "All Hall" Case Report With a-24 Month Follow Up. Stomatology Edu Journal 2017, 4, 208-217.

26- McKnight-Hanes, C., Myers, D. R., Dushku, J. C., Barenie, J. T. A comparison of general dentists' and pediatric dentists' treatment recommendations for primary teeth. Pediatric Dentistry 1991, 13, 344-348.

27- Gawthaman, M., Vinodh, S., Mathian, V. M., Vijayaraghavan, R., \& Karunakaran, R. . Apexification with calcium hydroxide and mineral trioxide aggregate: Report of two cases. Journal of Pharmacy \& Bioallied Sciences, 2013, 5 , 131-134.

28- Kimberlin, C. L., \& Winterstein, A. G. Validity and reliability of measurement instruments used in research. American Journal of Health-System Pharmacy, 2008, 65, 2276-2284.

29- Bell, R.A., Barenie, J.T., \& Myers, D.R. Trends and implications of treatment in predoctoral clinical paedodontics. Journal of dental education, 1987, 50, 722-5. 